\title{
Identification of the Lymphokine Soluble Immune Response Suppressor in Urine of Nephrotic Children
}

\author{
H. William Schnaper and Thomas M. Aune \\ Department of Pathology and Laboratory Medicine, The Jewish Hospital of St. Louis, and Departments of Pediatrics and Pathology, \\ Washington University School of Medicine, St. Louis, Missouri 63110
}

\begin{abstract}
Patients with minimal change nephrotic syndrome (MCNS) frequently have suppressed in vivo and in vitro immune responsiveness of uncertain etiology. Because increased suppressor cell activity has been associated with this disease, urines from MCNS patients were screened for activity of the lymphokine soluble immune response suppressor (SIRS), a product of concanavalin A- or interferon-activated suppressor $\mathbf{T}$ cells. Urines from untreated MCNS patients suppressed polyclonal plaque-forming cell responses of cultured splenocytes. This suppressive activity was identified as human SIRS by the following functional and physical criteria: (a) molecular weight estimated by gel filtration; (b) kinetics of suppression; (c) inhibition of suppression by catalase, levamisole, and 2-mercaptoethanol; (d) abrogation of activity by acid or protease treatment; (e) elution pattern on high performance liquid chromatography; and $(f)$ cross-reactivity with monoclonal antimurine SIRS antibodies. Suppressive activity disappeared from urine after initiation of treatment but before remission of symptoms. Urines were tested from 11 patients with MCNS, all of whom excreted SIRS. In addition, two nephrotic patients with acute glomerulonephritis and three nephrotic patients with membranoproliferative disease excreted SIRS, but other nephrotics and all nonnephrotic patients did not. These results indicate that excretion of SIRS occurs in certain cases of nephrotic syndrome and that the presence of SIRS in the urine is not accounted for solely by the presence of proteinuria or nephrosis. Serum from four nephrotic patients also contained SIRS, whereas neither serum nor urine from six normal subjects contained SIRS activity. The systemic presence of SIRS in these four patients, and the identification of SIRS in urines from a larger group of patients, suggest a possible role for SIRS in the suppressed immune responses often found in nephrotic syndrome.
\end{abstract}

\section{Introduction}

The nephrotic syndrome (NS) ${ }^{1}$ is characterized by extensive urinary loss of albumin leading to hypoalbuminemia, edema,

This work was presented in part to the meeting of the Society for Pediatric Research in San Francisco, CA, May 1984 (1984. Pediatr. Res. 18:369a) and was submitted in abstract form to the meeting of the American Society of Nephrology in Washington, DC, December 1984.

Address reprint requests to Dr. Schnaper, CSB-7, Pathology Research, The Jewish Hospital of St. Louis, 216 S. Kingshighway, St. Louis, MO 63110.

Received for publication 25 September 1984.

1. Abbreviations used in this paper: $\mathrm{CNBr}$, cyanogen bromide; Con $\mathrm{A}$, concanavalin A; HPLC, high performance liquid chromatography;

J. Clin. Invest.

(c) The American Society for Clinical Investigation, Inc.

0021-9738/85/07/0341/09 \$1.00

Volume 76 , July $1985,341-349$ and hypercholesterolemia (1). Patients with this syndrome frequently have suppressed clinical and in vitro immune responsiveness; the disease in which this phenomenon has been most extensively studied is minimal change nephrotic syndrome (MCNS). Unique attributes of MCNS include the lack of morphologic changes sufficient to account for proteinuria, the observed pattern of glomerular permselectivity (2), a frequent association with antecedent immunogenic stimuli (3), and the marked responsiveness of this disease to immunomodulatory agents. Patients with minimal change disease and other forms of NS show evidence of decreased cellular immunity (4). Furthermore, MCNS patient sera have been found to suppress lymphocyte proliferation (5) and to show cytotoxic activity (6). Enhanced suppressor cell function has also been described (7). Thus, clinical evidence of altered immunity appears to be associated with increased suppressor cell activity.

Suppressor cells have been shown in most in vitro model systems to act through release of soluble suppressor factors. One such system that has been well characterized is the soluble immune response suppressor (SIRS) pathway. SIRS is a product of mitogen- (8) or interferon-activated (9) murine or human (10) suppressor $\mathrm{T}$ lymphocytes that inhibits production of antibody when added at or near initiation of lymphocyte cultures. Suppression also occurs when factor is added late in the culture period after activation to its suppressive form, SIRS $_{\text {ox }}$, by reaction with low concentrations of $\mathrm{H}_{2} \mathrm{O}_{2}$ (11). Human SIRS has a molecular weight of 110,000-150,000 by chromatography on Sephacryl S-200 gel when eluted with buffers of physiologic ionic strength and 10,000-15,000 when eluted with high ionic strength buffers. It is acid and protease sensitive, and its in vitro activity is blocked by levamisole and catalase, which block activation of SIRS to SIRS mercaptoethanol (2-ME), which inactivates $\operatorname{SIRS}_{\mathrm{ox}}$ (10). Inhibition of suppression by these reagents and activation by peroxide are characteristic of both murine and human SIRS and are useful techniques in screening for the presence of SIRS in other systems (9).

To determine whether nephrotic patients might produce SIRS, we evaluated urines from children with MCNS in relapse and other proteinuric renal diseases for suppressive activity. Urine from all patients with MCNS and certain other nephrotic patients suppressed in vitro antibody-producing responses. This immunosuppressive activity was identical to human SIRS by functional and physical criteria. Suppressive activity disappeared from the urine after initiation of treatment, but before remission of NS. These results show that urines from certain nephrotic children contain the suppressor lymphokine SIRS.

MCNS, minimal change nephrotic syndrome; 2-ME, 2-mercaptoethanol; NS, nephrotic syndrome; PBMC, peripheral blood mononuclear cell(s); PFC, plaque-forming cell(s); PWM, pokeweed mitogen; $\mathrm{S}_{50}, 50 \%$ suppression; SIRS, soluble immune response suppressor; SIRS $_{\text {ox }}$, activated SIRS; SRNS, steroid-responsive nephrotic syndrome. 


\section{Methods}

Unless otherwise stipulated, all chemicals used were reagent grade and purchased from commercial sources.

Patient population. Patients studied in these experiments were under care of the Renal Division of St. Louis Children's Hospital and the Department of Pediatrics, Washington University School of Medicine. Urine was collected from patients who were evaluated for proteinuria. Diagnosis was made by using established criteria of clinical presentation, serum chemistries, radiography, and, where appropriate, renal biopsy $(1,3)$. In many of the nephrotic children, the following criteria indicated a diagnosis of "steroid-responsive nephrotic syndrome" (SRNS): (a) normal serum complement activity, $(b)$ no clinical or serologic evidence of collagen-vascular disease, $(c)$ relatively benign urine sediment, and $(d)$ good response to steroid therapy. In these patients biopsy was deferred. All subjects were 2-18 years of age.

Collection and treatment of urine samples. Timed collections of urine (usually for $12 \mathrm{~h}$ ) were obtained from patients and maintained briefly at $4^{\circ} \mathrm{C}$ until processing. Urines were concentrated if necessary to a volume of about $150 \mathrm{ml}$ by using an Amicon DC-2 concentrator (Amicon Corp., Danvers, MA), dialyzed against 40 vol of distilled water by using either the Amicon DC-2 or 3,500-mol wt cutoff cellulose dialysis tubing (Spectrum Medical Industries, Los Angeles, CA), lyophilized, and stored at $-20^{\circ} \mathrm{C}$ until use. Addition of protease inhibitors before processing did not affect activity in the earliest samples collected and was thus omitted thereafter. Lyophilized specimens contained over $90 \%$ protein by weight, as determined by the method of Lowry et al. (12).

Assay for antibody production. Human spleen cells were obtained aseptically from cadaver kidney transplant donors at the time of organ harvest, processed as described previously (11), and preserved frozen in liquid nitrogen until use. Alternatively, human peripheral blood mononuclear cells (PBMC) were obtained from healthy volunteers and isolated by centrifugation over Ficoll-sodium diatrizoate according to the method of Boyum (13). Spleen cells $\left(1 \times 10^{6}\right)$ or PBMC $\left(2 \times 10^{6}\right)$ were suspended in $1 \mathrm{ml}$ of sterile RPMI 1640 medium (K. C. Biologicals, Kansas City, MO) supplemented with glutamine, penicillin/ streptomycin, nonessential amino acids, and $10 \%$ fetal calf serum (Reheis Lot Nos. 58101 and 100361). Cells were cultured with pokeweed mitogen (PWM) at $6 \mu \mathrm{g} / \mathrm{ml}$ for $7 \mathrm{~d}$ in a $37^{\circ} \mathrm{C}, 5 \% \mathrm{CO}_{2}$, humidified atmosphere. After washing with Hanks' balanced salt solution, the cells were resuspended in L-15 medium (Washington University School of Medicine Cancer Center) supplemented with 3\% fetal calf serum and penicillin/streptomycin. Assay for antibody production employed a slide modification of the Jerne hemolytic plaque-forming cell (PFC) assay (14). A measured aliquot of cells was suspended in agarose with rabbit anti-human IgM antiserum (Boehringer-Mannheim, Indianapolis, IN) and sheep erythrocytes coated with staphylococcal protein A by the chromium chloride method (15). The mixture was allowed to gel on a glass slide. After a 4-h incubation at $37^{\circ} \mathrm{C}$, the slides were flooded with guinea pig complement (Rockland, Inc., Gilbertsville, PA) causing plaques of hemolysis to form around antibody-producing cells. The number of plaques per slide, and hence the number of PFC per culture, was determined by using dark-field illumination and a binocular dissecting microscope. Cell numbers were determined by counting on a hemocytometer and viability ascertained by trypan blue exclusion.

Experimental design. Because the concentration of protein in nephrotic urine is subject to marked variation, samples of urine from various patients were standardized according to a specific duration of excretion when resuspended in unsupplemented RPMI medium. During preliminary experiments, it was determined that optimal results were obtained when the amount excreted in $0.01 \mathrm{~h}$ was resuspended in 1 $\mathrm{ml}$ of medium. This usually represented about $1 \mathrm{mg} / \mathrm{ml}$, with a range of $0.5-5 \mathrm{mg} / \mathrm{ml}$. Resuspended urines were sterilized by membrane filtration (Gelman Sciences, Inc., Ann Arbor, MI) before addition to culture. Control responses were determined by the number of PFC/ culture when PWM alone was added to cultures. Background PFC responses, assessed in cultures without PWM, amounted to $<10 \%$ of PWM-stimulated culture responses and were not subtracted from these responses. All experiments were performed at least three times to assess reproducibility of findings. Portions of these experiments were also included in subsequent experiments as positive controls.

In screening for suppressive activity, a titration curve was generated from 0 to $60-90 \%$ suppression for each urine and the volume required to cause $50 \%$ suppression of control responses $\left(1 \mathrm{~S}_{50}\right.$ unit) determined graphically. Urines in which no suppressive activity was detected were retested over a broader titration range.

Fractionation of resuspended urines. $1 \mathrm{ml}$ of urine was fractionated by gel filtration on a $1.75 \times 28 \mathrm{~cm}\left(67.3 \mathrm{~cm}^{3}\right)$ column of Sephacryl S200 (Sigma Chemical Co., St. Louis, MO) in phosphate-buffered saline (PBS) or $0.4 \mathrm{M}$ pyridine- $0.4 \mathrm{M}$ acetic acid. The column was calibrated using aldolase (158,000 mol wt), bovine serum albumin (BSA) $(68,000$ mol wt) chymotrypsinogen A $(25,000 \mathrm{~mol} \mathrm{wt})$, and cytochrome $c$ $(13,000 \mathrm{~mol} \mathrm{wt})$. Fractions of $2 \mathrm{ml}$ were collected. Those eluted with pyridine-acetic acid were lyophilized and resuspended in PBS, and all fractions were sterilized before testing in cultures. Fractions containing suppressive activity were pooled for use in subsequent experiments.

Reverse-phase high performance liquid chromatography (HPLC) was performed by suspending lyophilized urine in $1.0 \mathrm{M}$ pyridine- 0.5 $\mathrm{M}$ acetic acid, pH 5.5 buffer. After clearing of particulate matter by centrifugation for 2 min in a Beckman Instruments, Inc. (Palo Alto, CA) microfuge, the solution was applied to a Lichrosorb RP-8 (10 $\mu$ M, E. Merck, Darmstadt, Federal Republic of Germany) column $(250 \times 4 \mathrm{~mm})$ equilibrated in the same pyridine-acetic acid buffer. Protein was eluted with an increasing gradient of $n$-propanol. Fractions from HPLC were lyophilized and resuspended in PBS or culture medium before testing for bioactivity. Protein content of the fractions was measured by the method of Lowry et al. (12) with BSA used as a standard.

Absorption of immunosuppressive activity using monoclonal antimurine SIRS antibodies. Monoclonal antimurine SIRS antibodies were obtained as described previously (16). Briefly, partially purified murine SIRS $\left(5 \times 10^{5} \mathrm{U}\right)$ in complete Freund's adjuvant was injected into Sprague-Dawley rats at biweekly intervals. Serum from each rat was bound to cyanogen bromide (CNBr)-activated Sepharose 6B (Sigma Chemical Co.), and the coupled beads were tested for ability to absorb murine SIRS activity from a standard solution $\left(10^{3} \mathrm{U} / \mathrm{ml}\right)$. Spleen cells from a rat demonstrating high-serum anti-SIRS activity were fused to the myeloma cell line SP 2/0 and supernates from hybridoma wells were tested for ability to absorb murine SIRS activity as described above. Four hybridomas producing antimurine SIRS antibody have been cloned. Each monoclonal antibody was coupled to CNBr-activated Sepharose 6B. A suspension of urine showing suppressive activity was incubated with the beads for $1 \mathrm{~h}$ at $4^{\circ} \mathrm{C}$. After removal of the beads by centrifugation the urine was tested for SIRS activity.

\section{Results}

Suppression of PFC response by urines from patients with $M C N S$. Resuspended urines were assayed for suppressive activity by adding graded amounts to PWM-stimulated lymphocytes $24 \mathrm{~h}$ after culture initiation. PFC responses were determined on day 7. Table I shows results of a typical experiment. Addition of urine from a healthy volunteer to which human serum albumin $(1 \mathrm{mg} / \mathrm{ml})$ had been added before processing did not significantly affect responses. However, $50 \mu$ l of urine from the four patients with MCNS, corresponding to $5 \%$ of culture volume, suppressed responses by over $70 \%$. The suppressive activity was not accounted for by a general cytotoxic effect of the urine in that a decrease in cell number and/or viability proportional to the reduction in PFC response was not observed.

Molecular weight of suppressor substance. To approximate the size of the suppressive moiety, urine with known suppressive activity was fractionated by gel filtration using Sephacryl S-200 chromatography. Fig. 1 shows the results of experiments 
Table I. Inhibition of PFC Responses by Nephrotic Urine*

\begin{tabular}{|c|c|c|c|c|}
\hline \multirow[b]{2}{*}{ Urine } & \multicolumn{4}{|l|}{$\mu \mathrm{l}$ added } \\
\hline & 0 & 20 & 50 & 200 \\
\hline & $\begin{array}{l}P F C / \text { culture } \\
\text { (n) }\end{array}$ & $\begin{array}{l}\text { PFC/culture } \\
\text { (n) }\end{array}$ & $\begin{array}{l}\text { PFC/culture } \\
\text { (n) }\end{array}$ & $\begin{array}{l}P F C / \text { culture } \\
\text { (n) }\end{array}$ \\
\hline Controlł & $5,600(2.20) \S$ & $6,300(2.06)$ & $5,600(2.42)$ & $5,980(2.22)$ \\
\hline F.W. & - & $4,100(2.28)$ & $1,210(2.00)$ & $710(2.22)$ \\
\hline J.H. & - & $1,420(1.98)$ & $1,400(2.32)$ & $1,360(1.98)$ \\
\hline L.C. & - & $2,820(2.36)$ & $1,450(1.98)$ & $260(2.16)$ \\
\hline R.L. & - & $3,650(2.44)$ & $1,380(1.98)$ & $2,060(2.30)$ \\
\hline
\end{tabular}

* Urines from nephrotic patients were dialyzed and lyophilized, and then resuspended in media. Aliquots were added to $2 \times 10^{6} \mathrm{PWM}$-stimulated lymphocytes $24 \mathrm{~h}$ after culture initiation. Polyclonal antibody production was determined $6 \mathrm{~d}$ later by the "reverse" PFC method using the Jerne hemolytic PFC assay. Units of activity in urines of patients F.W., L.C., and R.L. calculated from data in this table show 30,49 , and $32 \mathrm{U} / \mathrm{mg}$, respectively. Urine from patient J.H. required retesting at lower amounts to allow estimation of $\mathbf{S}_{\mathbf{5 0}}$ units of activity.

¥ Albumin was added to the control urine which was obtained from a normal volunteer. In other experiments, the presence or absence of albumin in the control urine did not affect responses.

$\S$ Numbers in parenthesis indicate number of viable cells $\times 10^{-6}$ in each culture. Nonviable cells (by trypan blue exclusion) represented 5-15\% of total cells in culture.

with both human, lymphocyte-derived SIRS (upper panel) and urine from a patient with MCNS (lower panel). When PBS is used as the elution buffer, suppressive activity migrates with an apparent molecular weight of $110,000-150,000$, in the two fractions preceding the BSA peak. When pyridine-acetic acid is used, the apparent molecular weight is $10,000-15,000$ for both lymphocyte SIRS and the urine suppressor factor. A shift

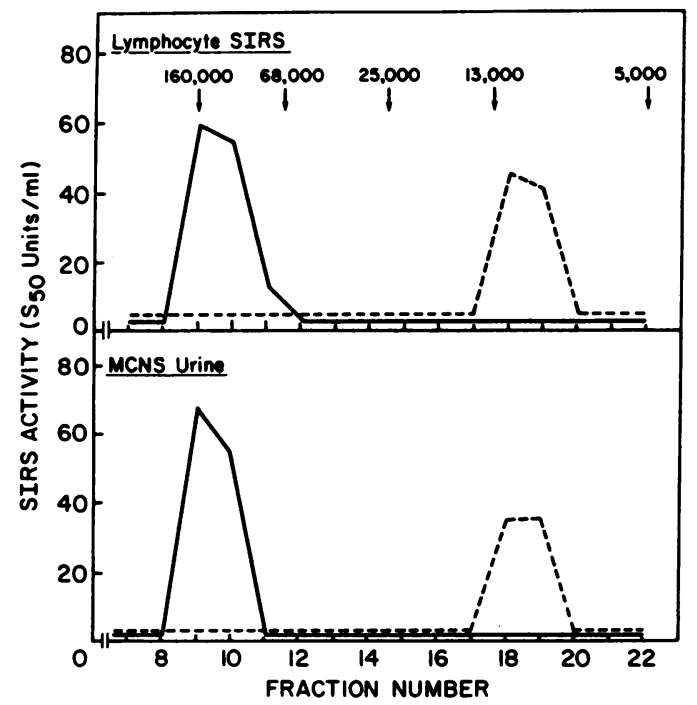

Figure 1. Fractionation of MCNS urine by Sephacryl S-200 chromatography. $1 \mathrm{ml}$ of reconstituted urine was fractionated in either PBS (-) or pyridine-acetic acid (-- ) and 2-ml fractions were collected. The upper graph shows a typical chromatographic pattern of lymphocyte SIRS activity. The lower graph shows that urine suppressive activity migrates identically. The column was calibrated using aldolase, BSA, chymotrypsinogen A, and cytochrome $c$. Comparable results were obtained from urine of five other patients with MCNS.
Table II. Effect of Day of Addition and Reaction with Peroxide on Urine Suppressive Activity

\begin{tabular}{llc}
\hline Urine factor added & Day added & PFC/culture \\
\hline & & $n$ \\
None & - & 1,785 \\
Factor $(30 \mu \mathrm{l})$ & 1 & 720 \\
Factor $(30 \mu \mathrm{l})$ & 6 & 1,680 \\
Factor $^{*}{ }^{*}(30 \mu \mathrm{l})$ & 6 & 665 \\
\hline
\end{tabular}

* Urine in this experimental group was treated with $\mathrm{H}_{2} \mathrm{O}_{2}$ at a final concentration of $10^{-6} \mathrm{M}$ for $20 \mathrm{~min}$ at $4^{\circ} \mathrm{C}$ before addition to culture. Media reacted with $10^{-6} \mathrm{M} \mathrm{H}_{2} \mathrm{O}_{2}$ added on day 6 did not affect responses. Separate experiments with urines from five different patients with MCNS gave comparable results.

in apparent molecular weight between the two buffer systems also occurs with murine SIRS, and appears to reflect binding of SIRS to other proteins under certain physiologic conditions (17).

Screening of urine for SIRS using characteristics of the SIRS pathway. Because of similarities between the migration patterns for SIRS and urine suppressive activity, the urine fractions from S-200 column chromatography which contained suppressive activity were pooled and screened for SIRS activity by using several characteristics of the SIRS pathway. To evaluate the kinetics of suppression and potential activation by peroxide, urine factor was added on day 1 or 6 to $7-d$ lymphocyte cultures. In the experiment shown in Table II, urine factor added early in the culture period suppressed PFC responses by $60 \%$. On day 6 , addition of urine factor did not cause suppression; however, urine factor reacted with $10^{-6} \mathrm{M}$ $\mathrm{H}_{2} \mathrm{O}_{2}$ for 20 min before addition to culture suppressed responses as well as factor added on day 1 . All five urines tested showed titratable activity on day 6 after reaction with peroxide. Adding peroxide-treated medium on day 6 did not significantly affect responses.

Cultures were also tested to determine whether addition of levamisole, catalase, and 2-ME blocked suppression by the urine factor. Table III shows the results of one such experiment. Control responses were suppressed by $65 \%$ by addition of 100

Table III. Effects of Inhibitors of SIRS Activity on Urine-derived Suppressor Factor Activity

\begin{tabular}{lll}
\hline Factor added* & Inhibitor & PFC/culture \\
\hline & & $n$ \\
None & - & 4,460 \\
$100 \mu \mathrm{l}$ & - & 1,600 \\
$100 \mu \mathrm{l}$ & Levamisole $(5 \mu \mathrm{g} / \mathrm{ml}$, day 1$)$ & 4,160 \\
$100 \mu \mathrm{l}$ & Catalase $(5,000 \mathrm{U} / \mathrm{ml}$, day 3$)$ & 4,000 \\
$100 \mu \mathrm{l}$ & 2-ME $\left(10^{-4} \mathrm{M}\right.$, day 3$)$ & 4,320
\end{tabular}

* In all cases, factor $(100 \mu \mathrm{l})$ was added to cultures on day 1 of a 7-d culture period. Addition of inhibitors alone did not significantly affect control responses. Suppressive activity in the urine of five different patients with MCNS was tested in this fashion and identical results were obtained in each instance. 
$\mu \mathrm{l}$ of the urine factor on day 1 . Addition of $5 \mu \mathrm{g}$ levamisole on day 1 blocked suppression in cultures containing the urine factor, as did addition of catalase $(5,000 \mathrm{U})$ or $2-\mathrm{ME}\left(10^{-4} \mathrm{M}\right)$ on day 3. Addition of levamisole, catalase, or 2-ME alone did not significantly affect responses.

To determine whether the urine factor was inactivated by acidification to $\mathrm{pH} 2$ or by incubation with protease, factor was acidified to $\mathrm{pH} 4$ or $\mathrm{pH} 2$ with $\mathrm{HCl}$, then neutralized after $3 \mathrm{~h}$ at $4^{\circ} \mathrm{C}$. Alternatively, urine was incubated with protease (Proteinase, Sigma Chemical Co.), $10 \mu \mathrm{g} / \mathrm{ml}$ for $3 \mathrm{~h}$ at $4^{\circ} \mathrm{C}$. All solutions were sterilized before addition to culture on day 1. In the experiment shown in Table IV, acidification to $\mathrm{pH} 4$ had no effect on suppressive activity, but acidification to $\mathrm{pH}$ 2 resulted in a loss of activity. Similarly, the urine factor was inactivated by protease. Thus, the ability of $\mathrm{H}_{2} \mathrm{O}_{2}$ to activate the urine factor to suppress responses when added shortly before culture assay, inhibition of suppression by agents that inhibit SIRS activity, and $\mathrm{pH}$ and protease sensitivity of the urine suppressive activity are all identical to those described for human lymphocyte SIRS. Taken together with the apparent molecular weight of the urine factor in physiologic and high ionic strength buffers, these data strongly support the possibility that suppressive activity of MCNS urine is due to the presence of SIRS.

Fractionation of urine suppressor factor by HPLC. Urine with suppressive activity and human lymphocyte SIRS obtained from concanavalin A (Con A)-activated PBMC were fractionated by reverse-phase HPLC on an RP-8 $(10 \mu \mathrm{M})$ analytical column. Protein was eluted by an increasing gradient of $n$ propanol. Fig. 2 compares the separation of biologic activity and protein for lymphocyte SIRS (upper panel) and for urine SIRS (lower panel). In both experiments, SIRS activity was separated from the major protein peaks present. Two major SIRS peaks eluted at the $5 \%$ propanol step-up and at $18 \%$ propanol on the linear gradient. A smaller, third peak of SIRS activity eluted at $8-9 \%$ propanol. All of the SIRS bound to the column; none was detected in the initial flow-through during column loading. Further, all activity loaded on the RP-8 column was recovered in the three active peaks; no SIRS activity was eluted by higher propanol concentration or by extended elution times. Identical findings were obtained with three different urines. The elution patterns from HPLC suggest that the urine SIRS and lymphocyte SIRS are similar proteins.

Table IV. Characteristics of Urine Suppressor Factor*

\begin{tabular}{lc}
\hline Factor treatment & PFC/culture \\
\hline & $n$ \\
Control response (no urine factor) & 9,150 \\
Untreated factor & 4,100 \\
pH 4 & 3,800 \\
pH 2 & 10,750 \\
Protease & 8,300 \\
\hline
\end{tabular}

* Urines were treated by adjusting $\mathrm{pH}$ to 4 or 2 with $\mathrm{HCl}$, then neutralizing with $\mathrm{NaOH}$ after $3 \mathrm{~h}$ at $4^{\circ} \mathrm{C}$. Alternatively, urine was incubated with protease, $10 \mu \mathrm{g} / \mathrm{ml}$, for $3 \mathrm{~h}$ at $0-4^{\circ} \mathrm{C}$ before addition to culture. Similar results were obtained in two other experiments with urine from other patients with MCNS.

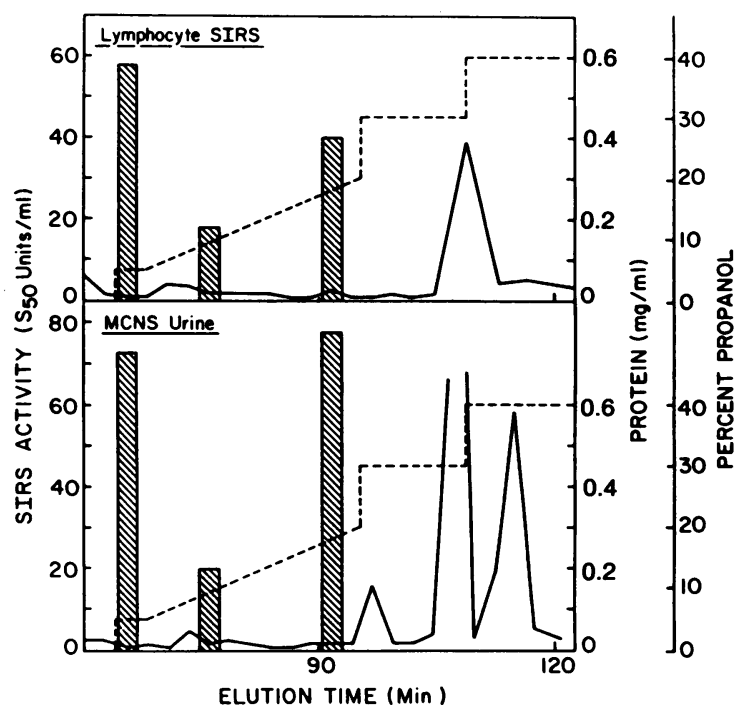

Figure 2. HPLC of SIRS and MCNS urine. Lyophilized, crude lymphocyte SIRS (3 mg) prepared from Con A-activated PBMC (top) or $5 \mathrm{mg}$ of lyophilized urine from a patient with MCNS (bottom) was applied to a Lichrosorb RP-8 $(10 \mu \mathrm{M})$ column equilibrated in $1.0 \mathrm{M}$ pyridine, $0.5 \mathrm{M}$ acetic acid, $\mathrm{pH} 5.5$, and eluted by reversephase HPLC using an increasing gradient of $n$-propanol (---). Protein concentration of eluted samples was determined by the method of Lowry et al. (12) (-) and SIRS activity (®) was determined by assay on spleen cell cultures. Three different urines from MCNS patients were fractionated by HPLC and identical results were observed in each instance.

Use of monoclonal antimurine SIRS antibodies to absorb urine suppressive activity. Four monoclonal antibodies to murine SIRS are available. Lymphocyte SIRS and urine SIRS were incubated with Sepharose beads coupled to each of the antimurine SIRS antibodies to determine whether suppressive activity was absorbed from the solution. Table $\mathrm{V}$ shows that

Table V. Absorption of Urine Suppressive Activity with Monoclonal Antimurine SIRS Antibody*

\begin{tabular}{|c|c|c|}
\hline & \multicolumn{2}{|l|}{ PFC/culture (n) } \\
\hline & $\begin{array}{l}\text { Lymphocyte SIRS } \\
100 \mu \mathrm{l}\end{array}$ & $\begin{array}{l}\text { Urine SIRS } \\
200 \mu \mathrm{l}\end{array}$ \\
\hline Control response & \multicolumn{2}{|c|}{7,600} \\
\hline Factor & 2,920 & 3,580 \\
\hline +Anti-SIRS & 5,520 & 6,180 \\
\hline +Anti-SIRS & 6,160 & 6,520 \\
\hline+ Anti-SIRS $_{3}$ & 5,840 & 7,900 \\
\hline +Anti-SIRS 4 & 6,000 & 9,300 \\
\hline +AA4.9¥ & 2,750 & 3,400 \\
\hline$+\mathrm{AC} 4.5 \ddagger$ & 2,160 & 3,560 \\
\hline
\end{tabular}

* Factor was incubated for $1 \mathrm{~h}$ at $4^{\circ} \mathrm{C}$ with monoclonal rat antimurine SIRS antibody coupled to CNBr-activated Sepharose beads, then filter sterilized before addition to culture on day 1 of a 7-d culture period. Similar results were obtained in five experiments with urine from other MCNS patients.

$\ddagger$ Monoclonal rat antibodies directed against murine, glutamic acidalanine-tyrosine synthetic polymer-specific suppressor factor. 
each antibody removed both human lymphocyte SIRS and urine SIRS from solution. When we used similar methods, rat antibodies against an antigen-specific murine suppressor factor (anti-GAT-TsF1, [GAT, synthetic polymer of L-glutamic acid $^{60}-$ L-alanine $e^{30}-$ L-tyrosine $\left.{ }^{10}\right]$ provided by Dr. Craig Sorensen, Washington University School of Medicine), did not absorb activity. This pattern of antigenic similarity supports the notion that human lymphocyte SIRS is similar to human urine SIRS and also show that both of these human SIRS proteins are similar to murine SIRS.

Disappearance of urine SIRS with treatment of nephrotic syndrome. To determine the relationship of urine SIRS activity to the disease state and treatment, serial urines were collected from patients from the time of initiation of treatment until remission of nephrotic syndrome. Fig. 3 shows the course of patient H.Y. undergoing steroid therapy. SIRS activity was present before the beginning of treatment, but disappeared from the patient's urine by day 4 or 5 of therapy. Although suppressive activity was markedly decreased by day 4 , protein excretion remained high, indicating that suppressive activity was not a function of protein excretion. Along with the decrease in proteinuria, onset of diuresis also followed the loss of suppressive activity. Table VI summarizes the courses of five patients followed by standard clinical methods during induction of remission with prednisone. In all patients, loss of suppressive activity preceded clinical response as indicated by the beginning of a decrease in urine protein concentration, onset of diuresis, and final disappearance of proteinuria. This temporal relationship was maintained regardless of whether the patient was studied during an initial presentation with MCNS or relapse, or whether remission occurred rapidly (4-5 d) or more slowly.

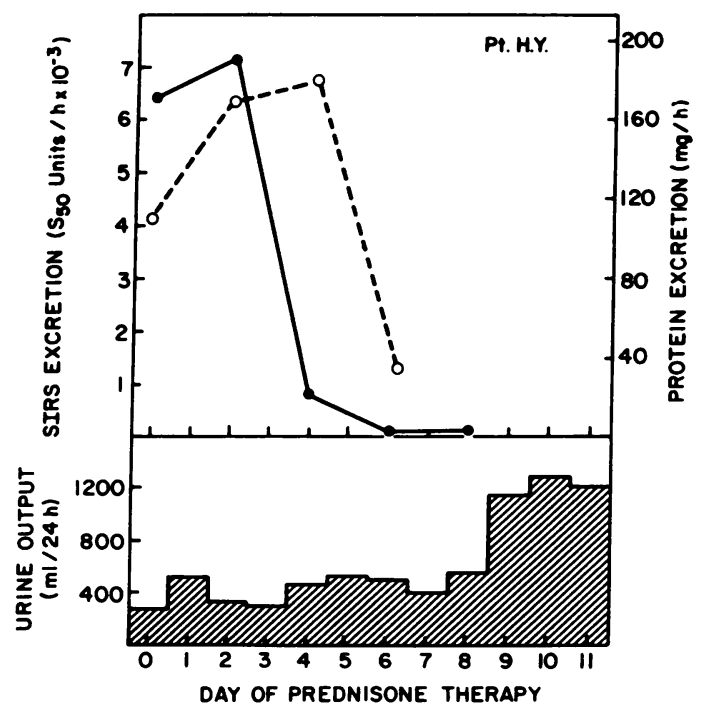

Figure 3. Response of nephrotic patient to treatment with prednisone. Serial urine collections were obtained from patient H.Y. (Pt. H.Y.), an 11-year-old boy with biopsy-proven MCNS, who was undergoing prednisone therapy. (๑) Urinary SIRS excretion; protein excretion ( 0 ) was determined by analysis of urine resuspended in medium using the method of Lowry et al. (12) (protein was not determined on the sample from day 8 because albumin was added to that urine before processing). Daily urine output is indicated by the bars on the lower graph.
Table VI. Comparison of Urine Suppressive Activity with Clinical Response during Prednisone Treatment of MCNS*

\begin{tabular}{|c|c|c|c|c|c|}
\hline \multirow[b]{2}{*}{ Patient } & \multicolumn{2}{|c|}{ SIRS activity } & \multicolumn{2}{|c|}{ Clinical response } & \multirow[b]{2}{*}{$\begin{array}{l}\text { First day } \\
\text { protein-free } \\
\text { urine }\end{array}$} \\
\hline & $\begin{array}{l}\text { Last } \\
\text { treatment } \\
\text { day } \\
\text { present }\end{array}$ & $\begin{array}{l}\text { First } \\
\text { treatment } \\
\text { day } \\
\text { absent }\end{array}$ & $\begin{array}{l}\text { Last day } \\
\text { maximal } \\
\text { urine } \\
\text { protein } \ddagger\end{array}$ & $\begin{array}{l}\text { Day of } \\
\text { onset of } \\
\text { diuresis§ }\end{array}$ & \\
\hline H.Y. & 2 & 4 & 5 & 9 & 11 \\
\hline J.M. & 0 & 3 & 3 & 5 & 14 \\
\hline L.G. & 0 & 1 & 1 & 4 & 7 \\
\hline E.V. & 1 & 3 & 5 & 6 & 8 \\
\hline B.L. & 7 & 12 & 12 & 14 & 16 \\
\hline
\end{tabular}

* Patients with known or suspected MCNS were given prednisone, $2 \mathrm{mg} / \mathrm{kg}$ orally beginning on day 1 . Serial urine collections were obtained and tested for suppressive activity as described in the Methods section of the text. The numbers in the table denote the day of treatment on which each observation was made.

‡ Urine protein was determined by use of dipsticks (Albustix, Ames, Elkhart, IN). "Maximal" protein excretion was indicated by a reading of $4+$ on all urine specimens.

$\S$ Defined as the first day of sustained, marked increase in urine output.

Screening of urine from patients with various proteinuric renal disorders. Urines from children with proteinuria of various etiologies were screened for suppressive activity on PFC cultures. Each sample was tested at least three times, and the mean number of suppressive units per milliliter of urine determined for each patient. The results of these assays are summarized in Table VII. Patients with steroid-responsive NS or biopsy-proven MCNS constitute the largest group of patients tested. All 11 steroid-responsive patients had suppressive activ-

Table VII. Summary of Screening for Urine SIRS Activity*

\begin{tabular}{llll}
\hline & $\begin{array}{l}\text { Patients with } \\
\text { urine SIRS } \\
\text { activity } \\
\text { present }\end{array}$ & $\begin{array}{l}\text { Patients with } \\
\text { urine SIRS } \\
\text { activity } \\
\text { absent }\end{array}$ & $\begin{array}{l}\text { Mean S } \\
\text { units/ml in } \\
\text { positive } \\
\text { urines }\end{array}$ \\
\hline Diagnosis & $n$ & $n$ & \\
MCNS, steroid-responsive & & & \\
$\quad$ Active disease & 11 & 0 & 55 \\
$\quad$ Remission & 0 & 2 & - \\
MCNS, steroid-unresponsive & 0 & 2 & - \\
Membranoproliferative & & & \\
$\quad$ glomerulonephritis & & & - \\
$\quad$ Nephrotic & 3 & 0 & - \\
$\quad$ Not nephrotic & 0 & 2 & - \\
Acute glomerulonephritis & 2 & 2 & - \\
Focal glomerulosclerosis & 0 & 2 & - \\
Systemic lupus & & & \\
$\quad$ erythematosus & & 2 & \\
$\quad$ Not nephrotic & 0 & 3 & \\
Other proteinuriał & 0 & &
\end{tabular}

* Each patient sample was screened at least three times, each time on cultures of different lymphocytes, for suppressive activity. The mean number of $\mathrm{S}_{50} \mathrm{U} / \mathrm{ml}$ was determined for each sample.

$\ddagger$ One patient each with diabetic nephropathy, congenital nephrosis, and transient proteinuria of undetermined etiology. 
ity, with a mean of 55 and a range of 38-100 U/ml. Molecular weight of urine SIRS was identical in six of six patients tested and was identical to that of lymphocyte-derived SIRS. SIRSmediated suppression was confirmed in these six samples by activation with peroxide, inhibition by reagents that block SIRS activity, or inactivation by protease or acidification to $\mathrm{pH}$ 2. Urines from two patients with MCNS in remission who were no longer on steroid therapy did not contain SIRS activity. Furthermore, two patients who were unresponsive to steroids but had normal glomerular histology on biopsy also did not excrete SIRS.

Three nephrotic patients with type I membranoproliferative glomerulonephritis showed considerable suppressive activity in their urine, with a mean of $57 \mathrm{U} / \mathrm{ml}$. Suppression from one of these urines was confirmed as SIRS-mediated by all the criteria described above, including antibody absorption. After treatment with steroids, two patients became nonnephrotic; in one, steroids were discontinued. During remission of nephrosis neither patient excreted SIRS in the urine, although persistent proteinuria and hypocomplementemia indicated that the primary nephritic process was still active.

Urines were obtained from four patients with apparent acute glomerulonephritis. Three of these patients were biopsied because of atypical features which included mild nephrotic syndrome. Two of the biopsied patients (one diagnosed morphologically as having immune complex nephritis, the other, "nephritis with omniglomerular sclerosis") had small amounts of suppressive activity ( 5 and $17 \mathrm{U} / \mathrm{ml}$, respectively).

Neither of two patients with focal glomerulosclerosis had urine SIRS despite massive proteinuria. Urine from two nonnephrotic children with systemic lupus erythematosus who were proteinuric did not contain SIRS. One patient each with diabetic nephropathy, congenital nephrosis, and transient proteinuria of undetermined etiology (not nephrotic) also had no urinary SIRS activity.

Assay of serum for SIRS activity. Because some patients with nephrosis manifest decreased in vivo and in vitro immune responses, sera were evaluated to determine whether SIRS activity may be present systemically in patients who excrete SIRS. The suppressive effect of patient sera on in vitro PFC responses was assayed in a manner identical to that used in screening urines. Sera from all three patients with MCNS who were tested showed suppressive activity, with a mean of 83 $\mathrm{U} / \mathrm{ml}$ (Table VIII). The serum from a patient with membranoproliferative glomerulonephritis also contained SIRS, $115 \mathrm{U} /$

Table VIII. SIRS Activity in Sera of Nephrotic Patients*

$\begin{array}{llll} & \begin{array}{l}\text { Subjects with } \\ \text { SIRS activity } \\ \text { present }\end{array} & \begin{array}{l}\text { Subjects with } \\ \text { SIRS activity } \\ \text { absent }\end{array} & \begin{array}{l}\text { Mean } \text { So }_{\mathbf{0}} \\ \text { units/ml in } \\ \text { positive sera }\end{array} \\ & n & n & \\ \text { MCNS patients } & 3 & 0 & 83 \\ \text { MPGN patient } & 1 & 0 & 115 \\ \text { Healthy controls } & 0 & 6 & -\end{array}$

* Each serum was assayed for ability to suppress lymphocyte PFC responses. Suppression was confirmed as being SIRS-mediated by absorbing serum with rat antimurine SIRS antibodies and retesting for ability to suppress PFC responses. ml. Suppression was confirmed as being SIRS mediated in all cases by absorption of suppressive activity from the serum with anti-SIRS antibody coupled to Sepharose. Sera from six healthy volunteers did not contain SIRS.

\section{Discussion}

It has long been recognized that nephrotic syndrome may be associated with disordered cellular and humoral immunity. Bacterial infection, particularly primary peritonitis, frequently occurs during active disease (3). MCNS patients have decreased skin reactivity to tuberculin and dinitrochlorobenzene which improves with remission of symptoms (4). Alterations in lymphocyte subpopulations have been noted (18). In addition, serum immunoglobulin levels are abnormal, with relapseassociated increased IgM and decreased IgG levels reported in MCNS (19) and other forms of nephrotic syndrome (20). These abnormalities in immune responsiveness have been further evaluated using in vitro techniques. Patient sera have been found to be toxic to control lymphocytes $(6,21)$; increased serum migration inhibitory factor activity (22), and increased monocyte cytotoxicity against cultured renal epithelial cells (23) have also been described. Several studies have shown decreased lymphocyte proliferation in the presence of sera from nephrotic patients in relapse $(5,24,25)$. A heat-stable substance in patient serum has been described which binds to normal lymphocytes and decreases the proliferative response to mitogens (26). Increased Con A-activated suppressor cell activity has also been reported in MCNS patients in relapse compared to healthy controls, patients in remission, and patients with glomerulonephritis (7). Although these findings appear most striking in MCNS, they may not be restricted to minimal change disease; several of the studies cited above found similar abnormalities in other forms of nephrotic syndrome $(6,21,22,24-26)$.

Despite this considerable body of evidence, the mechanism of immune suppressive activity is unclear. It has been suggested that suppression could be a nonspecific effect of the elevated serum lipid levels seen in these patients (27). An agent that has a demonstrable role in basic immunoregulatory systems has not previously been associated with nephrotic syndrome. Because patients with MCNS have elevated Con A-activated suppressor $T$ cell activity and because it is known that Con A-activated suppressor $T$ cells release the lymphokine, SIRS, it seemed appropriate to seek evidence of SIRS production in these patients.

The SIRS suppressor pathway has been studied extensively in mice, and murine SIRS has been purified to homogeneity (17). In addition to its effect on antibody secretion, it also inhibits cell division and protein secretion by a variety of normal and neoplastic cell lines (10). Further, SIRS blocks guanosine triphosphate-dependent microtubule assembly in vitro (28). Thus, its effects are not limited to regulation of the immune system. Human SIRS, although not as well characterized, has been investigated sufficiently to establish that it constitutes an analogue of the murine system. Both lymphokines have characteristic kinetics of suppression and share certain physicochemical properties. Also, catalase, levamisole, and 2-ME interfere with suppression in both systems. Employed together, these characteristics constitute an effective tool for screening for murine (10) or human (11) SIRS activity in various in vitro models of immunosuppression. 
To determine whether SIRS was produced by patients with NS, urines of MCNS patients were evaluated for ability to suppress PFC responses. Suppressive activity was found in urines from all patients with SRNS in relapse. Table IX summarizes characterization of this suppressive activity and compares the urine factor to human lymphocyte SIRS. The two factors have similar migration patterns on gel filtration with physiologic and high ionic strength buffers. HPLC of each factor is identical, yielding two larger peaks accounting for $\sim 80 \%$ of total activity at $5 \%$ and $18 \%$ propanol, respectively, and a smaller peak at $8-9 \%$ propanol. Both factors must be added near the time of culture initiation to suppress responses but when activated by reaction with $\mathrm{H}_{2} \mathrm{O}_{2}$ can cause suppression when added late in the culture period. Catalase and levamisole, which block activation of SIRS, and 2-ME, which inactivates SIRS $_{\text {ox }}$, each inhibit urine suppressor factor activity. Both lymphocyte SIRS and urine SIRS were acidlabile and inactivated by protease. Finally, monoclonal antimurine SIRS antibodies, but not irrelevant antibodies, absorbed both human lymphocyte and urine-derived SIRS activity from solution. Application of these criteria clearly demonstrates that SIRS, which has been characterized previously by in vitro techniques, is produced in vivo and is related to a disease state.

The relationship between urinary SIRS excretion and the suppressed immune responses found in MCNS has not been defined. However, we have found that suppressor cells activated by a variety of stimuli including Con $A(8,10)$, distinct types of interferon $(9,14)$, and histamine (16) all act through release of SIRS. Because murine SIRS inhibits antibody-producing responses when administered in vivo (29), it is conceivable that SIRS production by activated suppressor cells could account for the immunosuppression associated with MCNS. The presence of SIRS activity in the sera of four patients with nephrosis of immune etiology is consistent with this hypothesis. The origin of urine SIRS, whether SIRS is produced only by certain nephrotics, and the mechanism by which SIRS is excreted in the urine remains unclear. However, it is important

Table IX. Comparison of Human Lymphocyte and Urine SIRS

\begin{tabular}{|c|c|c|}
\hline & Lymphocyte SIRS & MCNS urine SIRS \\
\hline \multicolumn{3}{|l|}{ Molecular weight } \\
\hline PBS & $110,000-150,000$ & $110,000-150,000$ \\
\hline Pyridine-acetic acid & $10,000-15,000$ & $10,000-10,000$ \\
\hline \multicolumn{3}{|l|}{ HPLC } \\
\hline Peak 1 & $5 \%$ propanol & $5 \%$ propanol \\
\hline Peak 2 & 8-9\% propanol & 8-9\% propanol \\
\hline Peak 3 & $18 \%$ propanol & $18 \%$ propanol \\
\hline Optimal time of addition & Day 1 & Day 1 \\
\hline Activation by peroxide & + & + \\
\hline \multicolumn{3}{|l|}{ Inhibition by catalase } \\
\hline and levamisole & + & + \\
\hline Inhibition by $2-\mathrm{ME}$ & + & + \\
\hline Acid lability & pH 2 & pH 2 \\
\hline Inactivation by protease & + & + \\
\hline \multicolumn{3}{|l|}{$\begin{array}{l}\text { Absorption of activity by } \\
\text { antimurine SIRS }\end{array}$} \\
\hline antibodies & + & + \\
\hline
\end{tabular}

to note that other lymphokines or growth factors have been detected in urine $(30,31)$. Comparison of urine and serum SIRS levels in patients with nephritis and nephrosis, and levels of SIRS release from T lymphocytes of MCNS patients and normal controls, should help address some of these issues.

In the data reported here, urinary SIRS excretion was not a function of proteinuria. This is best demonstrated by the disappearance of SIRS from the urine of patients with MCNS after initiation of corticosteroid therapy but before decrease in protein excretion. Other patients had significant proteinuria without detectable urine SIRS activity. For example, although systemic lupus erythematosus has been associated with immune abnormalities (32), two children with lupus nephritis did not excrete SIRS. Two children with membranoproliferative glomerulonephritis without NS also did not excrete SIRS. In these and other patients, protein excretion clearly does not result in SIRS excretion. Furthermore, although all patients who excreted SIRS were nephrotic, only certain causes of nephrotic syndrome were associated with urine SIRS activity. Children with MCNS or NS secondary to glomerulonephritis excreted SIRS, but patients with focal glomerulosclerosis or congenital NS did not do so. The data obtained in screening are grouped in Table $X$ according to presence and type of proteinuria. Of nine patients without proteinuria, including seven healthy controls and two patients in long-term remission of MCNS, none excreted SIRS. Similarly, none of seven patients with nonnephrotic proteinuria excreted SIRS. In patients with SRNS before treatment or nephrosis with glomerulonephritis, 15 of 16 had urinary SIRS activity. In contrast, none of five patients who were nephrotic for other reasons excreted SIRS. In addition, patients who received corticosteroids for SRNS but had not yet entered remission also did not excrete SIRS. Thus, SIRS excretion is not simply a function of the nephrotic state. Although the numbers reported here are small, it is striking that only those patients who had NS from diseases classically associated with an immune pathogenesis excreted SIRS. This suggests that urinary excretion of SIRS may be related in some way to the immunologic etiology of these diseases.

Table X. Relationship between Proteinuria and SIRS Excretion*

\begin{tabular}{lll}
\hline & $\begin{array}{l}\text { Patients with } \\
\text { urine SIRS } \\
\text { activity present }\end{array}$ & $\begin{array}{l}\text { Patients with } \\
\text { urine SIRS } \\
\text { activity absent }\end{array}$ \\
\hline $\begin{array}{ll}\text { Nondition } \\
\begin{array}{l}\text { Proteinuria without nephrotic syndrome } \\
\text { Nephrotic syndrome associated with } \\
\text { steroid responsiveness or } \\
\text { glomerulonephritis }\end{array}\end{array}$ & 0 & 9 \\
$\begin{array}{l}\text { Nephrotic syndrome not associated with } \\
\text { steroid responsiveness or } \\
\text { glomerulonephritis }\end{array}$ & 15 & 7 \\
$\begin{array}{l}\text { SRNS after initiation of steroid } \\
\text { therapył }\end{array}$ & 0 & 1 \\
\hline
\end{tabular}

* This table summarizes results from patient listed in Table IX and healthy volunteers.

¥ Urines were obtained from these patients before occurrence of a significant decrease in protein excretion (see Table VI). 
The exact nature of this relationship is unclear. However, abnormal immune responses in MCNS, the sensitivity of this disease to immunomodulatory agents, and remission of nephrosis with inhibition of cell-mediated immunity led Shalhoub (33) to propose that MCNS is a primary immunologic disorder with renal manifestations. Furthermore, experimental evidence has indicated that lymphocytes may mediate depletion of glomerular polyanion (34), the component of the glomerular filter that retards albumin excretion (35); and that macrophages may mediate experimentally induced albuminuria $(36,37)$. Thus, it is of interest that levamisole, an inhibitor of the SIRS pathway, has been found to induce remission of MCNS (38). The disappearance of SIRS activity with steroid treatment, before entry into remission, may only indicate that urinary SIRS is a steroid-sensitive epiphenomenon of conditions that relate to and possibly precede clinical nephrotic syndrome. However, because SIRS affects cells outside the immune system, these data are also consistent with the possibility that SIRS may be involved in the pathogenesis of some cases of nephrotic syndrome. Further investigation may clarify the relationship of SIRS production to the disease state in these patients.

\section{Acknowledgments}

We appreciate the assistance of the C.U.R.E. unit, Washington University School of Medicine, in obtaining human spleen. We are indebted to Drs. Saulo Klahr and Carl Pierce for reviewing the manuscript. Nancy Fieldhammer provided essential technical assistance; Barbara Wollberg and Paula Ryan provided valuable secretarial and administrative assistance.

This work was support in part by grant 1431 from the Council for Tobacco Research, USA, Inc., and by the Monsanto Company. Dr. Schnaper is the recipient of Clinical Investigator Award K08 AM01317 from the National Institute of Arthritis, Diabetes and Digestive and Kidney Diseases; Dr. Aune is the recipient of a Junior Faculty Research Award from the American Cancer Society.

\section{References}

1. Brenner, B. M., and J. H. Stein, editors. 1982. Contemporary Issues in Nephrology, Vol. 9. Nephrotic Syndrome. Churchill Livingstone, Inc., New York. 1-308.

2. Robson, A. M., and B. R. Cole. Pathologic and functional correlations in the glomerulopathies. In Immune Mechanisms in Renal Disease. N. B. Cummings, A. F. Michael, and C. B. Wilson, editors. Plenum Publishing Corp., New York. 109-127.

3. Grupe, W. E. 1979. Childhood nephrotic syndrome: clinical associations and response to therapy. Postgrad. Med. 65:229-236.

4. Fodor, P., M. T. Saitua, E. Rodriguez, B. Gonzales, and L. Schlesinger. 1982. T-cell dysfunction in minimal change nephrotic syndrome of childhood. Am. J. Dis. Child. 136:713-717.

5. Moorthy, A. V., S. W. Zimmerman, and P. M. Burkholder. 1976. Inhibition of lymphocyte blastogenesis by plasma of patients with minimal change nephrotic syndrome. Lancet. I:1160-1162.

6. Ooi, B. S., A. R. Orlina, and L. Masaitis. 1974. Lymphocytotoxins in primary renal disease. Lancet. II:1348-1350.

7. Osakabe, K., and K. Matsumoto. 1981. Concanavalin A-induced suppressor cell activity in lipoid nephrosis. Scand. J. Immunol. 14: 161-166.

8. Rich, R. R., and C. W. Pierce. 1974. Biological expressions of lymphocyte activation. III. Suppression of plaque-forming cell responses in vitro by supernatant fluids from concanavalin A-activated spleen cell cultures. J. Immunol. 112:1360-1368.

9. Aune, T. M., and C. W. Pierce. 1982. Activation of a suppressor
T-cell pathway by interferon. Proc. Natl. Acad. Sci. USA. 79:38083812.

10. Schnaper, H. W., C. W. Pierce, and T. M. Aune. 1984. Identification and initial characterization of concanavalin A- and interferon-induced human suppressor factors: evidence for a human equivalent of murine soluble immune response suppressor (SIRS). $J$. Immunol. 132:2429-2435.

11. Aune, T. M., and C. W. Pierce. 1984. Mechanism of SIRS action at the cellular and biochemical level. In Lymphokines, Vol. 9. E. Pick, editor. Academic Press, Inc., New York. 257-277.

12. Lowry, O. H., N. J. Rosebrough, A. L. Farr, and R. J. Randall. 1951. Protein measurement with the Folin phenol reagent. J. Biol. Chem. 193:265-275.

13. Boyum, A. 1968. Isolation of mononuclear cells and granulocytes from human blood. Scand. J. Clin. Lab. Invest. 97(Suppl.):77-89.

14. Schnaper, H. W., T. M. Aune, and C. W. Pierce. 1983. Suppressor T cell activation by human leukocyte interferon. J. Immunol. 131:2301-2306.

15. Sweet, G. H., and F. L. Welborn. 1971. Use of chromium chloride as the coupling agent in a modified plaque assay of cells producing antiprotein antibody. J. Immunol. 106:1407-1410.

16. Aune, T. M., H. W. Schnaper, and C. W. Pierce. 1985. Soluble immune response suppressor (SIRS). Methods Enzymol. In press.

17. Aune, T. M., D. R. Webb, and C. W. Pierce. 1983. Purification and initial characterization of the lymphokine soluble immune response suppressor. J. Immunol. 131:2848-2852.

18. Kerpen, H. O., J. G. Bhat, R. Kantor, B. Gauthier, K. R. Rai, R. G. Schacht, and D. S. Baldwin. 1979. Lymphocyte subpopulations in minimal change nephrotic syndrome. Clin. Immunol. Immunopathol. 14:130-136.

19. Giangiacomo, J., T. G. Cleary, B. R. Cole, P. Hoffsten, and A. M. Robson. 1975. Serum immunoglobulins in the nephrotic syndrome. A possible cause of minimal change nephrotic syndrome. $N$. Engl. J. Med. 293:8-12.

20. Heslan, J. M., J. P. Lautie, L. Intrator, C. Blanc, G. Lagrue, and A. T. Sobel. 1982. Impaired IgG synthesis in patients with the nephrotic syndrome. Clin. Nephrol. 18:144-147.

21. Barna, B. P., S. Makker, R. Kallen, R. Valenzuela, S. D. Deodhar, M. Yeip, D. Leto, M. A. Verbic, S. Rajaraman, and S. Govindarajan. 1983. A lymphocytotoxic factor(s) in plasma of patients with minimal change nephrotic syndrome: partial characterization. Clin. Immunol. Immunopathol. 27:272-82.

22. Mallick, N. P., R. J. Williams, H. McFarlane, W. McN. Orr, G. Taylor, and G. Williams. 1972. Cell-mediated immunity in nephrotic syndrome. Lancet. I:507-509.

23. Eyres, K., N. P. Mallick, and G. Taylor. 1976. Studies of cellular immune responses in patients with minimal change nephropathy. Dial. Transplant. Nephrol. 11:533-539.

24. Beale, M. G., P. E. Hoffsten, A. M. Robson, and R. P. MacDermott. 1980. Inhibitory factors of lymphocyte transformation in sera from patients with minimal change nephrotic syndrome. Clin. Nephrol. 13:271-276.

25. Martini, A., M. A. Vitiello, S. Siena, V. Capelli, and G. Guazo. 1981. Multiple inhibitors of lectin-induced lymphocyte proliferation in nephrotic syndrome. Clin. Exp. Immunol. 45:178-184.

26. Iitaka, K., and C. D. West. 1979. A serum inhibitor of blastogenesis in idiopathic nephrotic syndrome transferred by lymphocytes. Clin. Immunol. Immunopathol. 12:62-71.

27. Lenarsky, C., S. C. Jordan, and S. Ladisch. 1982. Plasma inhibition of lymphocyte proliferation in nephrotic syndrome: correlation with hyperlipidemia. J. Clin. Immunol. 2:276-281.

28. Irons, R. D., R. W. Pfeiffer, T. M. Aune, and C. W. Pierce. 1984. Soluble immune response suppressor (SIRS) inhibits microtubule function in vivo and microtubule assembly in vitro. J. Immunol. 133: 2032-2036.

29. Schnaper, H. W., T. M. Aune, and C. W. Pierce. 1983. In vivo suppression of murine plaque-forming cell responses with the lymphokine, soluble immune response suppressor. Fed. Proc. 42:452. (Abstr.) 
30. Kawakita, M., T. Miyake, S. Kishimoto, and M. Ogawa. 1982. Apparent heterogeneity of human megakaryocyte colony and thrombopoeisis-stimulating factors: studies on urinary extracts from patients with aplastic anemia and idiopathic thrombocytopenic purpura. $B r . J$. Haematol. 52:429-438.

31. Kimball, E. S., S. F. Pickeral, J. J. Oppenheim, and J. L. Rossio. 1984. Interleukin 1 activity in normal human urine. $J$. Immunol. 133:256-260.

32. Steinberg, A. D., H. R. Smith, C. A. Laskin, B. J. Steinberg, and J. S. Smolen. 1982. Studies of immune abnormalities in systemic lupus erythematosus. Am. J. Kidney Dis. 2(Suppl.):101-110.

33. Shalhoub, R. 1974. Pathogenesis of lipoid nephrosis. A disorder of T-cell function. Lancet. II:556-559.

34. Kreisberg, J. E., D. B. Wayne, and M. J. Karnovsky. 1979. Rapid and focal loss of negative charge associated with mononuclear cell infiltration early in nephrotoxic serum nephritis. Kidney Int. 16: 290-300.

35. Brenner, B. M., T. H. Hostetter, and H. D. Humes. 1978. Molecular basis of proteinuria of glomerular origin. N. Engl. J. Med. 298:826-833.

36. Schreiner, F. G., R. S. Cotran, V. Pardo, and E. Unanue. 1978. A mononuclear cell component in experimental immunological glomerulonephritis. J. Exp. Med. 147:369-384.

37. Holdsworth, S. R., T. J. Neale, and C. B. Wilson. 1981. Abrogration of macrophage-dependent injury in experimental glomerulonephritis in the rabbit. J. Clin. Invest. 68:686-698.

38. Tanphaichitr, P., D. Tanphaichitr, J. Sureeratanan. 1980. Treatment of nephrotic syndrome with levamisole. J. Pediatr. 96:490493. 